\title{
motice
}

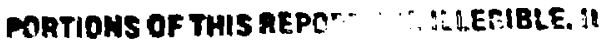

has been reproduced ficir. - a arate

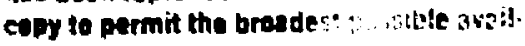

UCRL-90481

sbility.

PRFIPIINT

$\cos --90601$

DES: $0150 \%$

\section{Measuring Transient Radiation Effects in Optical Fibers}

\author{
M. D. Rotter \\ D. R. Jander
}

This paper was prepared for submittal to Proceedings of the Society of Photo-Optical

Instrumentation Engineers

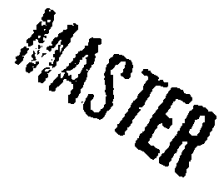

July 1984

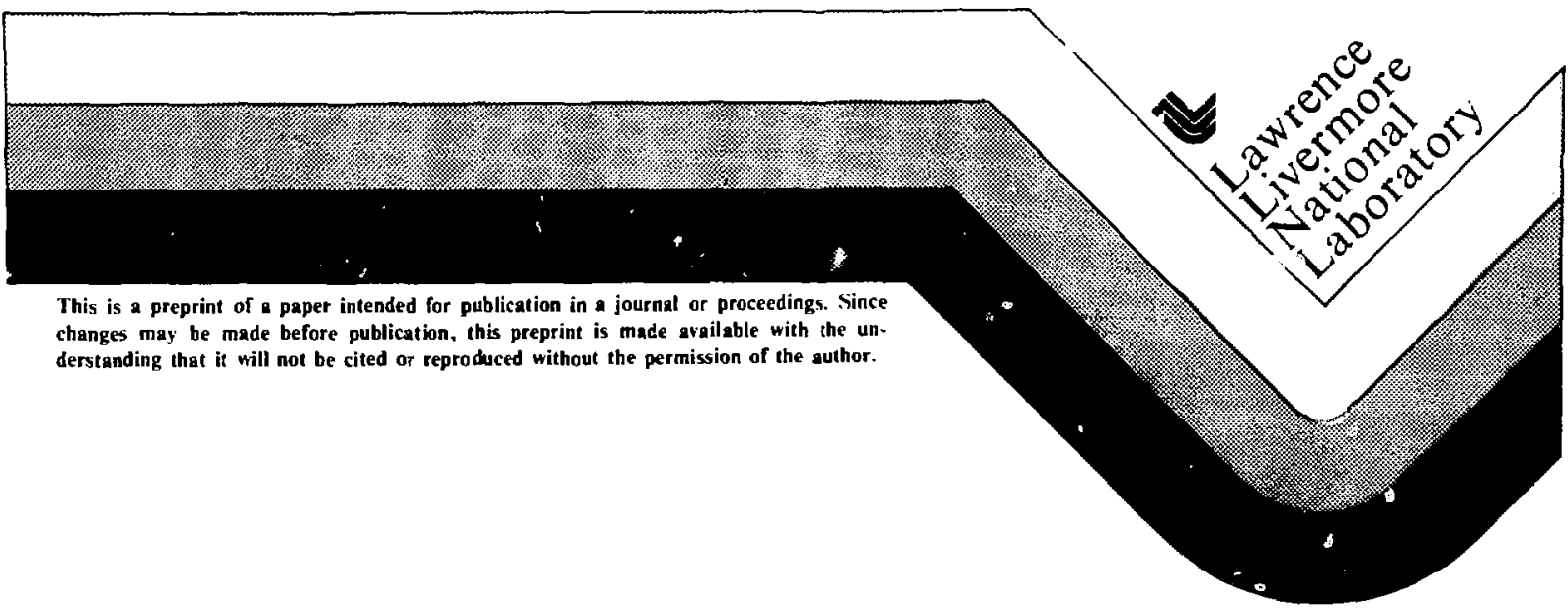




\title{
Mrsuling transient radistion pelferso in sptical fiters \\ Mark I3. Kotter and Mansla $h$, sader \\ Lawrence Iivermore Valional Laboralory. Linive"sity af Calitarnia \\ P.O. Jnx \$08, Livermors, Californis $9 \$ 550$
}

\begin{abstract}

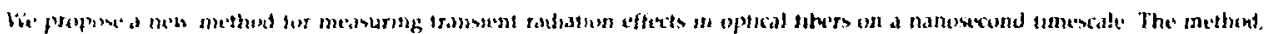

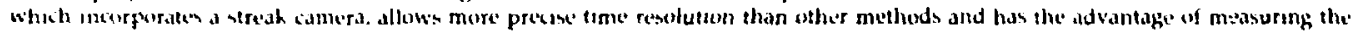

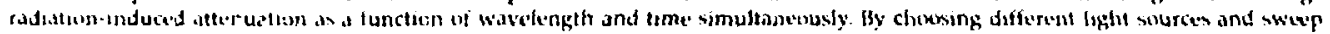

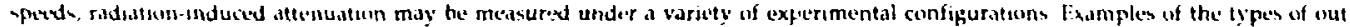
fus obiatled with our method are given.
\end{abstract}

\section{Introduction}

A ratiatun covironment damages optizal fiburs, causing then to darken. An understanding of this darkening process is impurtant. enectally when fibers are applied in a gamma-ray delection experment. In this case, we are interested in otserving dannge as it wiar, (n) the fibers in the enperimental timescales. Previous methods of measuring th is damage have either been limited to a single wavelength for a given dise, or to timescales longer than useful to our work. ${ }^{2,}$. We describu a methed that can be used to ublain data of fiber-darkening over o broud speural range and at timestales that can vary from nanoseconds to microseconds.

\section{Description of metnod}

In Figure 1, we show a bluck diagram of our system. The surce of the radiation is a Febetron Mudel-706 electron gun. This gun emsts a $1.5-\mathrm{m}$ p putwe of $400 \mathrm{keV}$ (average energy) electrons. A 10-mil thick piece of aluminum at the end of the gun serves as a scatferer to ensure a uniform dese' distribution over the fiber. The irsadiated area is defined via the collimator. By chanbing the distance betwees the end of the gur and the fjbers, the dose to the fibers can be varied by three orders of magnitude. The entire apparatus is uperated at at mispheric pressure.

W. uned two fibers in this measurement. One tiber is connected to a xenon flashlamp. The other fiber records the amount of Cerenkev light generded in the fibers. This information is used to subtract the Cerenkov light from the data fiber. The two fibers are then attoched to the fure-optics of the streak camera.

A whematic uf une-half of the fore-optics is shown in Figure 2. The light from the fiber is cullimated by a $54 \mathrm{~mm} f / 1.8$ lens and dispersed ty the $\$ 200$ lines $/ m m$ grating. The light is then collected and focused by another $54 \mathrm{~mm} f / 1.8$ iens onto a stop. This stop defines the spectral range uf interest. An $88 \mathrm{n} n \mathrm{~m} / \mathrm{f} / \mathrm{l}$ lens, designed to operate at a $1: 1$ conjugate ratio, focuses the image at the stop sinto the photecathedic of the streak camera.

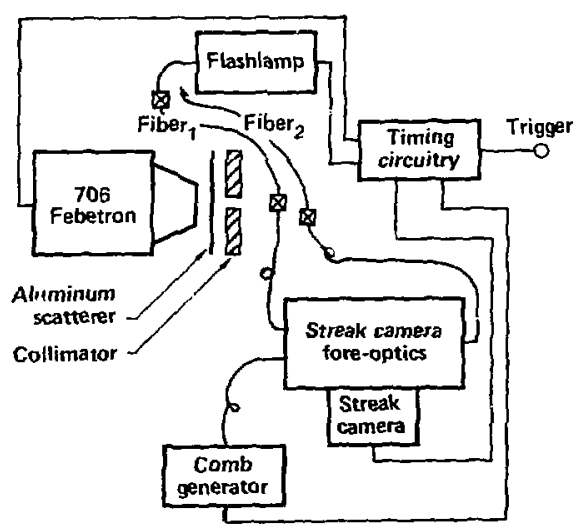

Figure 1. Fiber-darkening system.

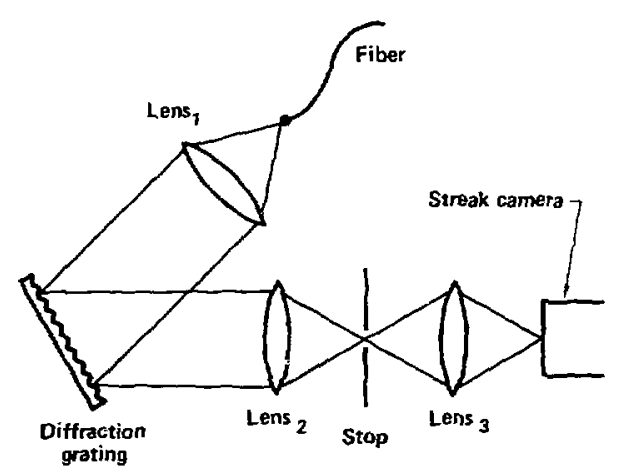

Figure 2. Fore-optics system. 


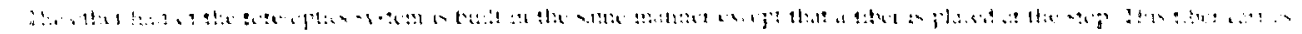

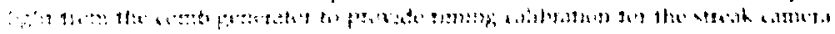

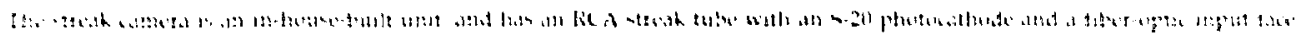

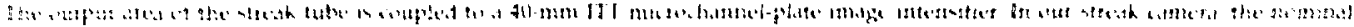

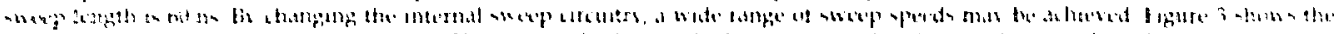

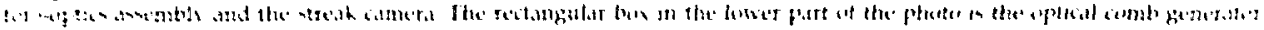

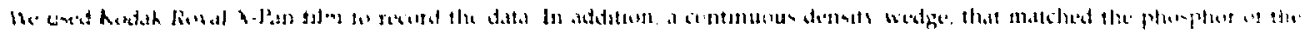

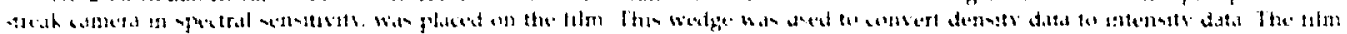

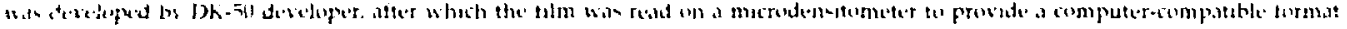

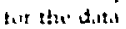

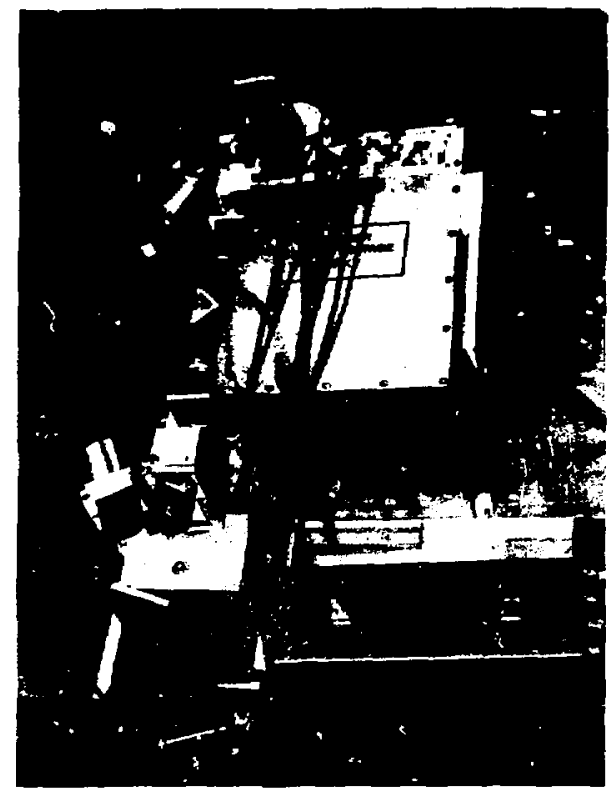

Figure 3. Photo of fore-optics assembly, streak camera, and comb generator.

\section{Typical results}

As our purpose is to describe a new method for measuring transient radiatun demage in optical fibers, we give only a couple representative results. The fiber used was a Raychem pure silica core with a glase cladding. The core diameter was $125 \mu \mathrm{m}$. In Figure 4. we show the data as it appears after it has been processed by the microdensitermeter. The Cerenken pulse and the abrupt fiberdarkening are plainly visible. For both sides, the spectral coverage is from 650 to $\$ 10 \mu \mathrm{m}$, with $810 \mathrm{~nm}$ occurring near the center of the picture. The sharp pulses running down the center of the picture come from the comb generator and ars 4 ns apart.

Data analysis is performed using the many image-processing codes that exist on our CDC-7600 computers. In Fioures 5 and 6 , we show the induced attenuation as a function of time for low and high doses as applied to the fiber.

in Figure 5 , the applied dose is $1.2 \mathrm{Mrad}$ as measured by radiachromic film. The upper curve corresponds to a 10-nm wide slice centered at $67.5 \mathrm{~nm}$ : the lower curve is for a $10-\mathrm{nm}$ wide slice centered at $800 \mathrm{~nm}$.

In Figure 6 , the applied dose is $150 \mathrm{krad}$ as measured by radiathromic film. The wavelength ranges are the same as those for Figure 5. 


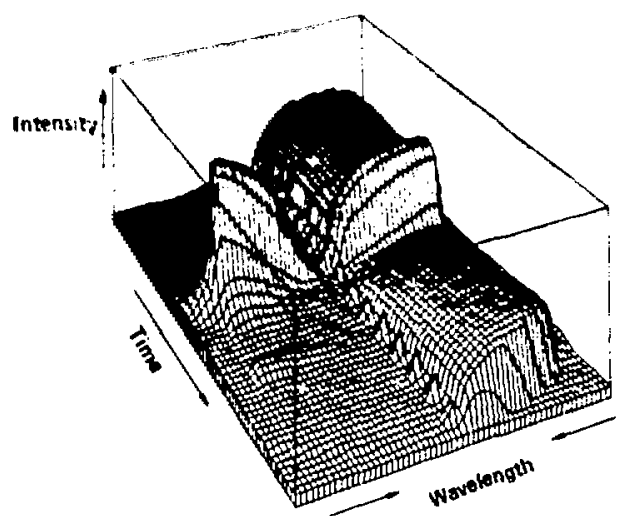

Nigure t. Datuafler heing degitized

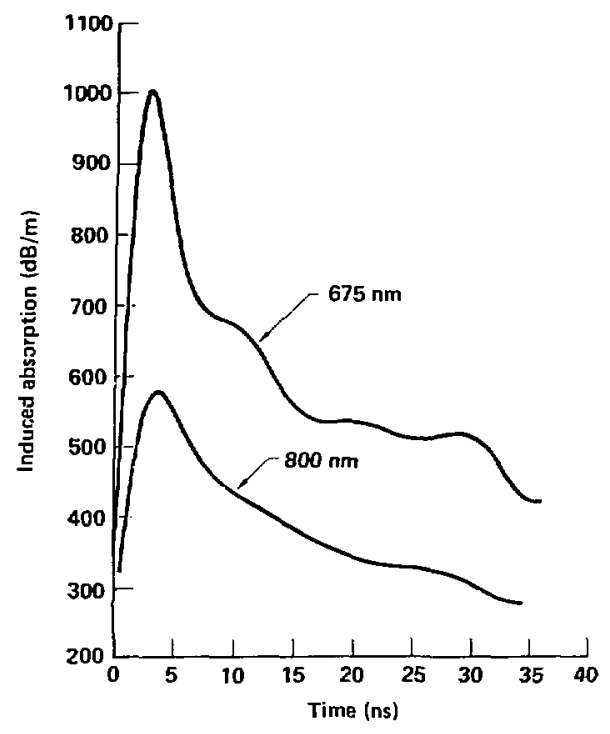

Figure 5. Fiber-darkening results (high dose)

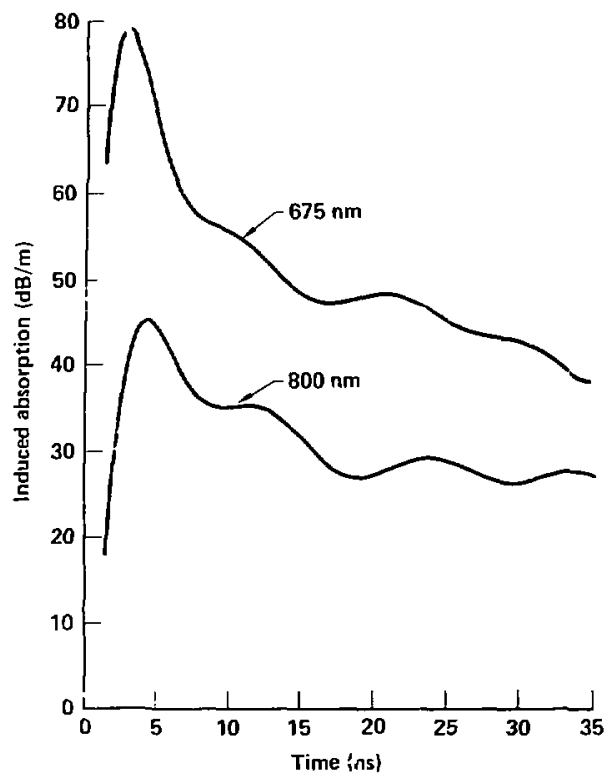

Figure 6 . Fibor-darkening resulis (low dose). 


\title{
concleaiun
}

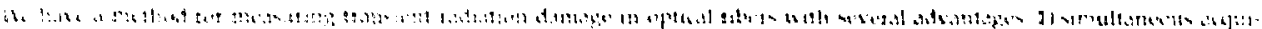

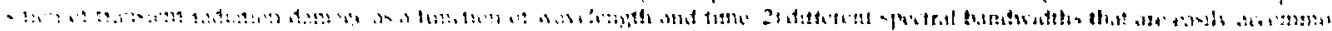

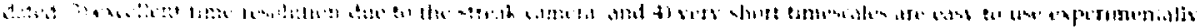

\section{Achnowledgments}

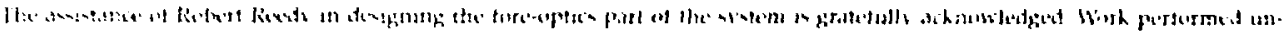

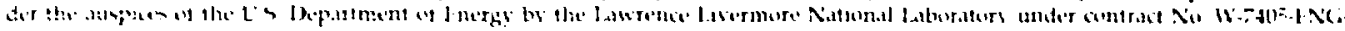
ir:

\section{Referenies}

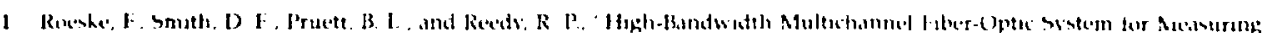

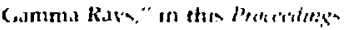

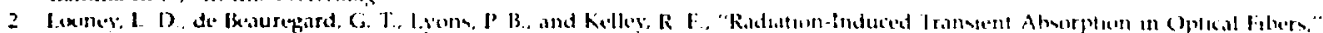

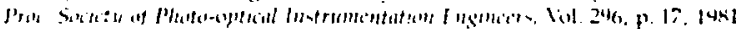

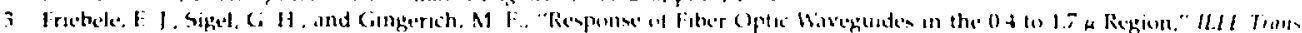

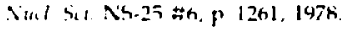

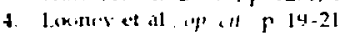

\section{DISCLAIMER}

\begin{abstract}
This report was prepared as an account of work sponsored by an agency of the United States Government. Neither the United States Governmen:1 no: any agency thereof, nor any of their employecs, makes any warranty, express or implied, or assumes any legal liability or responsibility for the acsuracy, completeness, or usefulness of at.y information, apparatus, product, or process disclosed, or represents that its use would not infringe privately owned rights. Reference herein to any specific commercial product, process, or service by trade name, trademark, manufacturer, or otherwise does not necessarily constitute or irnply its endorsement, recommendat:on, or favoring by the United States Government or any agency thereof. The vievs and opinions of authors expressed herein do noi necessarily state or reflect those of the United States Government or any agency ihcreof.
\end{abstract}

